\title{
Severe Case of Autoimmune Thrombocytopenia First Diagnosed in Pregnancy
}

\section{Erstdiagnose einer Autoimmunthrombozytopenie in der Schwangerschaft mit schwerem Verlauf}

Authors

Affiliations
K. Bolten ${ }^{1}$, A. Salama ${ }^{2}$, A. Thomas ${ }^{1}$, J. Eucker ${ }^{3}$, W. Henrich

${ }^{1}$ Klinik für Geburtsmedizin CCM, Charité, Berlin

2 Institut für Transfusionsmedizin, Charité, Berlin

${ }^{3}$ Medizinische Klinik mit Schwerpunkt Onkologie und Hämatologie CCM, Charité, Berlin

\author{
Key words \\ - pregnancy \\ - ITP \\ $\checkmark$ autoimmune \\ thrombocytopenia \\ - obstetrics \\ - premature birth \\ - coagulopathy \\ Schlüsselwörter \\ - Schwangerschaft \\ - ITP \\ - Autoimmun- \\ thrombozytopenie \\ - Geburtshilfe \\ - Frühgeburt \\ - Koagulopathie
}

Deutschsprachige Zusatzinformationen online abrufbar unter: www.thieme-connect.de/ ejournals/toc/gebfra

received 17.7.2013

revised 2.11.2013

accepted 5.11.2013

Bibliography

DOI http://dx.doi.org/ 10.1055/s-0033-1360149

Geburtsh Frauenheilk 2013; 73 : 1252-1255 @ Georg Thieme

Verlag KG Stuttgart · New York . ISSN 0016-5751

\section{Correspondence}

Dr. Kristina Bolten

Charité

Klinik für Geburtsmedizin CCM

Charitéplatz 1

10117 Berlin

kristina.bolten@charite.de

\section{Abstract \\ $\nabla$}

We report on a 28-year old primigravida who presented in the second trimester with sudden onset of bleeding tendencies and thrombocytopenia of $2 / \mathrm{nL}$ during the first manifestation of autoimmune thrombocytopenia (ITP). Therapy with intravenous immunoglobulins (IVIG) and steroids was initiated but could not prevent renewed bleeding incidents and recurrent thrombocytopenia in the long term, thus premature delivery by Caesarean section in the $32+3$ week of pregnancy could not be avoided. The bleeding complications could only be mastered by multiple thrombocyte transfusions. Because the ITP remained refractory to therapy in the postpartum period a thrombopoietin receptor agonist (TPO-RA) was administered. This led to an increase in the thrombocyte count which was later stabilised by prednisolone alone.

\section{Introduction}

\section{$\nabla$}

Thrombocytopenia (thrombocytes $<150 / \mathrm{nL}$ ) is, second to anaemia, the most frequent haematological disease observed during pregnancy [1]. According to the above-mentioned definition, almost one in ten pregnant women exhibit thrombocytopenia at the end of pregnancy [2]. The most common cause for this is pregnancy-associated thrombocytopenia which occurs from the middle of the second trimester. Its aetiology has not yet been conclusively clarified. It is assumed that physiological changes taking place in this period, such as haemodilution as well as an elevated activation of thrombocytes and thus increased clearance, play a role [3]. The thrombocyte counts of afflicted patients are as a rule in excess of $80 / \mathrm{nL}$ and the pregnancy-associated thrombocytopenia is not accompanied by bleed-

\section{Zusammenfassung \\ $\nabla$}

Wir berichten von einer 28-jährigen Erstgravida, die sich im 2. Trimenon mit plötzlich aufgetretener Blutungsneigung und Thrombozytopenie von 2/nl bei der Erstmanifestation einer ITP vorstellte. Die initiierte Therapie mit intravenösen Immunglobulinen (IVIG) und Steroiden konnte erneute Blutungsereignisse und rezidivierende Thrombozytopenien langfristig nicht verhindern, sodass eine vorzeitige Entbindung per Sectio nach Applikation der Lungenreifeinduktion in $32+3$ SSW nicht vermeidbar war. Die Blutungskomplikationen konnten nur durch multiple Thrombozytentransfusionen beherrscht werden. Aufgrund postpartaler Therapierefraktärität der ITP wurde ein Thrombopoetin-Rezeptoragonist (TPO-RA) appliziert, der zum Anstieg der Thrombozytenzahl führte, die später mithilfe von Prednisolon allein stabilisiert werden konnte.

ing complications nor is it associated with a poorer outcome for mother or baby [3].

Another cause of isolated thrombocytopenia is autoimmune thrombocytopenia (ITP). In contrast to pregnancy-associated thrombocytopenia, ITP can occur in all trimesters and is characterised by low thrombocyte counts with haemorrhagic tendencies. Almost one third of all afflicted pregnant women thus require a therapeutic intervention or prevention during their pregnancies [4].

\section{Case Report}

$\nabla$

A 28-year-old primigravida presented in $26+3$ weeks of pregnancy with haematomas on her legs and left arm that had occurred spontaneously within one week ( $\bullet$ Fig. 1).On the day of admission she additionally exhibited epistaxis as well as petechia of the skin and oral mucous mem- 


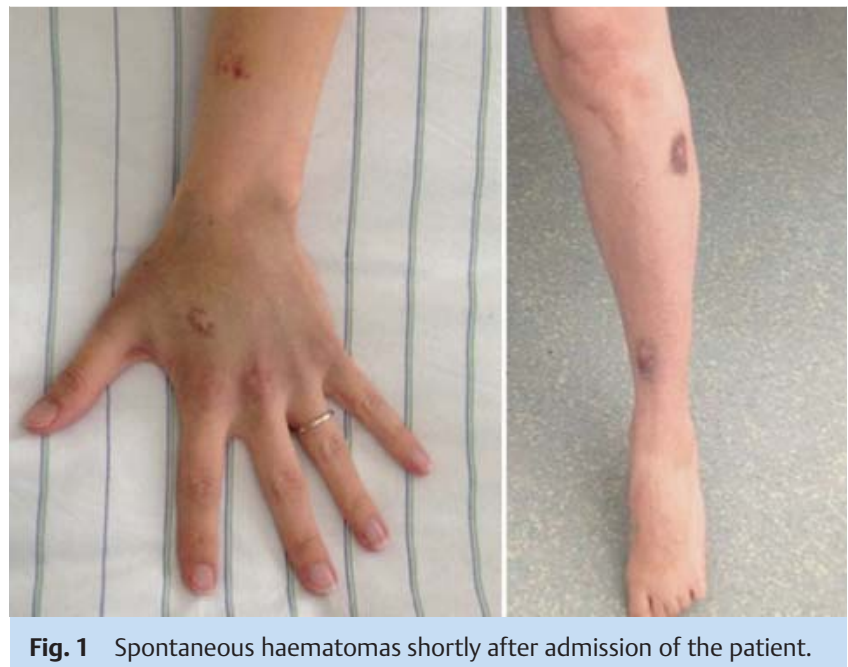

Fig. 1 Spontaneous haematomas shortly after admission of the patient.

branes. Clinical examination did not reveal any further complaints. She did not suffer from headache or upper abdominal pain. Her vital signs were normal. Previous diseases, and coagulopathies in particular, were not known and the family history was inconspicuous. She was not taking any medication. A blood analysis in the first trimester had been normal.

Laboratory tests revealed a thrombocytopenia of $2 / \mathrm{nL}$ with mild anaemia of $9.4 \mathrm{~g} / \mathrm{dL}$ and an unremarkable differential blood count. Other parameters, above all those relating to haemolysis, liver function and coagulation (haptoglobin, LDH, ALT, AST, bilirubin, aPTT, INR, thrombin time, antithrombin, fibrinogen), were also inconspicuous, so that HELLP syndrome was excluded.

Initially the patient received $1 \mathrm{~g}$ tranexamic acid to reduce the risk of bleeding; this drug inhibits fibrinolysis via complex formation with plasminogen and additionally improves the adhesion, activation and aggregation of thrombocytes. She also received 4 thrombocyte concentrates.

Foetal ultrasound showed an age-appropriate foetal development without signs of placental haemorrhage. Ultrasonography of the mother's upper abdomen was normal with no sign of splenomegaly. Antibody screening for APS, SLE and virus serology were performed without pathological findings. Bone marrow cytology showed megakaryocytes within the normal range. The clinical course and findings suggested the diagnosis of ITP.

Intravenous administration of immunoglobulins (IVIG) was started immediately (total dose $2 \mathrm{~g} / \mathrm{kg}$ body weight over 3 days) in combination with prednisolone $100 \mathrm{mg}$ i.v. The thrombocyte count increased under this regimen and the patient was discharged on the 8th day free of complaints.

In spite of intermittent administration of IVIG and continued steroid therapy, a renewed dramatic decrease of the thrombocyte count to $0 / n L$ was seen 24 days later. The patient was again treated with IVIG (total dose $2 \mathrm{~g} / \mathrm{kg}$ BW over 2 days) in combination with dexamethasone ( $40 \mathrm{mg} / \mathrm{d}$ over 4 days), but without success so that delivery by Caesarean section was indicated. The patient was readmitted and after a course of betamethasone for RDSprophylaxis as well as further thrombocyte transfusions the baby was delivered without any problems in $32+3$ weeks. Due to the elevated haemorrhagic risk the Caesarean section was performed under general anaesthesia. The newborn boy did not show any bleeding tendencies and revealed unremarkable thrombocyte counts in his first days of life (day 1 263/nL, day 3 192/nL).
In spite of renewed IVIG administration and prednisolone therapy as well as multiple thrombocyte transfusions (14 TCs and $2 \mathrm{ECs}$ within the first week after delivery) a very dynamic course with rapid drops in thrombocyte numbers was observed in the postoperative period. Another course of dexamethasone i.v. over 4 days was administered, but without success ( 0 Fig. 2). Thus, treatment with the thrombopoietin receptor agonist (TPO-RA) eltrombopag (Revolade ${ }^{\circledR}$ ) was initiated; this finally led to a good response with rapidly increasing thrombocyte counts. As no experience with this drug in breast-feeding mothers was available the baby had to be weaned.

Six months after starting therapy the patient's thrombocyte counts were stable at about $60 / \mathrm{nL}$ under a maintenance dose of $5 \mathrm{mg}$ prednisolone/day. She has been free of bleeding since her release from hospital. The TPO-RA was rapidly tapered within 6 weeks as there is only little experience about the long-term effects of this drug.

In spite of his premature birth, her son has developed normally and continues to grow at the 25 th percentile.

\section{Discussion}

$\nabla$

Autoimmune thrombocytopenia affects about 2 per 1000 pregnant women and amounts to around $5 \%$ of all thrombocytopenias in pregnancy [5]. For comparison, pregnancy-associated thrombocytopenia accounts for about $80 \%$ of all thrombocytopenias in pregnancy [2]. If a thrombocytopenia is diagnosed for the first time in the 1st or early in the 2nd trimester or is accompanied by values of less than $50 / \mathrm{nL}$, the most probable diagnosis is, however, ITP [6,7]. It is caused by the occurrence of IgG autoantibodies against thrombocyte antigens, whereupon a more rapid degradation of the thrombocytes in the reticuloendothelial system takes place. Antibodies against megakaryocytic antigens might also play a role [8]. However, the detection of autoantibodies does not constitute a diagnostic criterion; only the exclusion of all other causes of thrombocytopenia with the detection of an inadequately high megakaryocyte count in bone marrow permits the diagnosis of ITP.

In adults, ITP is generally a chronic disease requiring regular monitoring of the thrombocyte count and, if necessary, therapeutic interventions.

For ITP during pregnancy there are no fixed threshold values as to when and how therapy should be undertaken, instead, an individual case-by-case assessment is recommended by the guidelines of the American Society of Hematology 2011 [9]. The International Consensus Report 2010 suggests a threshold value of 20 to 30 thrombocytes/nL as an orientation [10].

Primary therapeutic options in pregnancy are IVIG and steroids. IVIG modulate the function of the immune system through an influence on the cellular (e.g. B- and T-cells, dendritic cells) and soluble (e.g. complement, cytokines, autoantibodies) components [11]. Depending on the gestational age, splenectomy remains as ultima ratio although the available data do not allow a definitive conclusion. Whether TPO-RAs offer an alternative option to treat ITP in pregnancy has not yet been clarified: so far only one case report is available on this topic [12].

Thrombocyte concentrates should be administered only in exceptional situations since due to the extremely accelerated degradation of thrombocytes - as in our case - they cannot furnish any long-term effects and effectively "go up in smoke". 


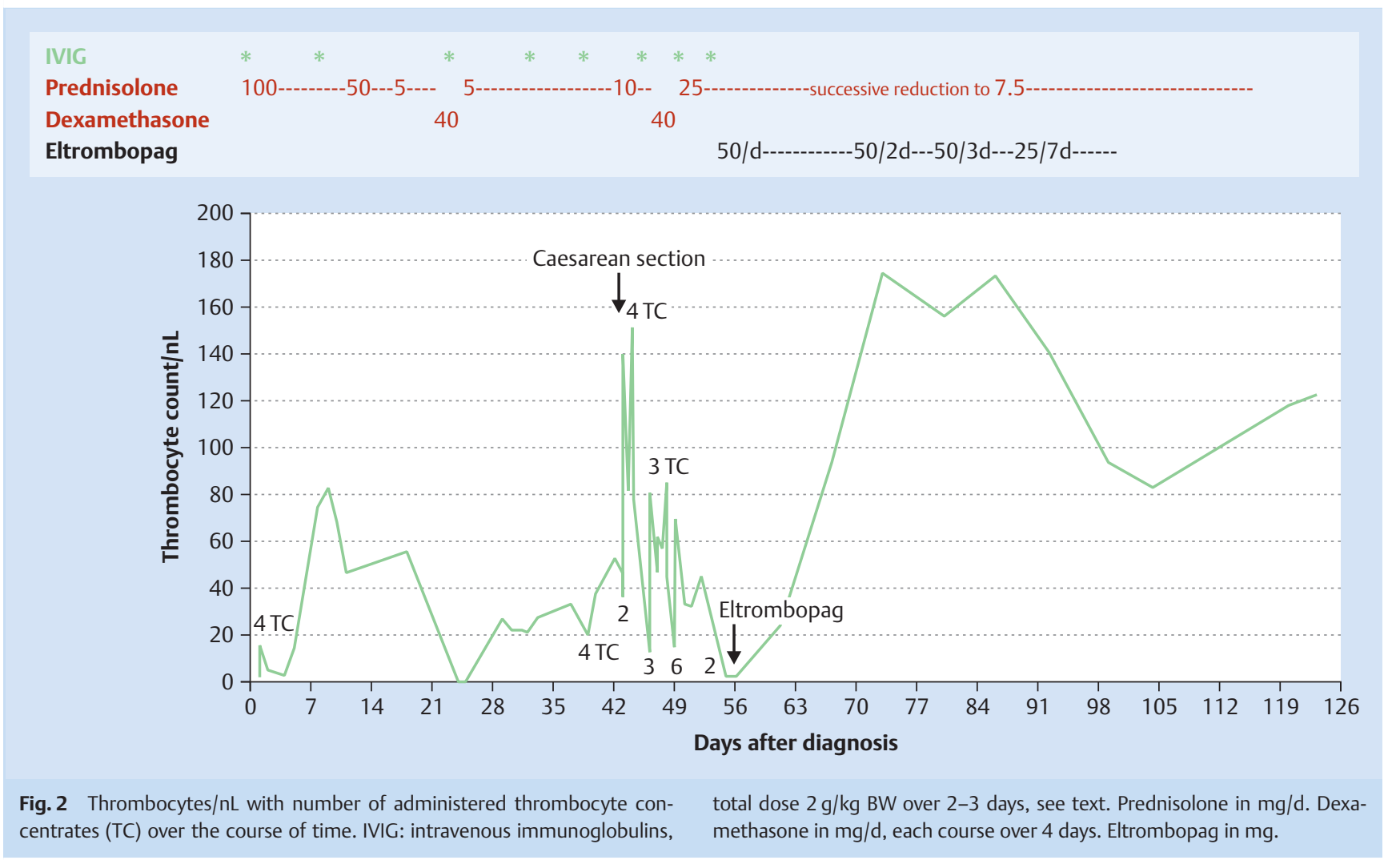

With advancing gestational age an induced premature birth becomes an option as more therapeutic possibilities are available post-partum, e.g. TPO-RA. These act through a stimulation of megakaryocytes and thus thrombopoiesis via binding to thrombopoietin receptors on haematopoietic stem cells and megakaryocytes. They have been approved in Germany since 2010 for the treatment of ITP after splenectomy.

In our patient, due to the therapy-resistant nature of the ITP and the haemorrhagic tendencies, we opted for a premature delivery via Caesarean section in hope for a better response to therapy after delivery and in order to be able to escalate therapy with options not available during pregnancy.

In general, when treating patients with ITP in pregnancy individualised thrombocyte monitoring should be performed so that therapy with thrombocyte boosters can be initiated in time if necessary. ITP in the mother is not an indication for Caesarean section, neither for maternal nor for foetal indications. For a spontaneous delivery thrombocyte count should not be below $50 / \mathrm{nL}$ according to guidelines of the British Society of Haematology. However, spontaneous deliveries without complications have been reported with markedly lower counts $[4,13]$. For delivery by Caesarean section under spinal anaesthesia thrombocyte count should be at $80 / \mathrm{nL}$ or more. It must nevertheless be emphasised that there is little factual evidence to substantiate the reported threshold values.

Babies of mothers with ITP are usually - as in our case - healthy, but may suffer from transient neonatal immunothrombocytopenic purpura on account of the placental permeability of IgG, accordingly the thrombocyte count should be monitored during the first week of life. A relevant thrombocytopenia of less than $20 / \mathrm{nL}$ occurs in less than $5 \%$ of cases $[14,15]$. The rate of haemorrhagic complications is low, but if therapy is necessary, IVIG and/ or steroids may be given. IVIG therapy for the mother seems to have a protective effect for the unborn child, as IVIG can pass through the placental barrier already at 13 weeks and above all in the 3rd trimester $[16,17]$.

\section{Conclusion}

$\nabla$

In all patients who are for the first time diagnosed with an isolated thrombocytopenia during pregnancy ITP should be considered, especially if this occurs before the 3rd trimester and with thrombocytes below 50/nL. Depending on the course of the disease, patients with ITP require individualised, more or less intense monitoring of their thrombocyte counts in order to be able to initiate a possibly necessary therapy in good time.

In the case reported here, a short-term postpartum use of TPO-RA led to a partial remission of the ITP without causing any complications for mother or child.

\section{Conflicts of Interest}

$\nabla$

None.

\section{References}

1 Sullivan CA, Martin jr. JN. Management of the obstetric patient with thrombocytopenia. Clin Obstet Gynecol 1995; 38: 521-534

2 Gernsheimer T, James AH, Stasi R. How I treat thrombocytopenia in pregnancy. Blood 2013; 121: 38-47

3 Gernsheimer T. Thrombocytopenia in pregancy: is this immune thrombocytopenia or ...? Hematology Am Soc Hematol Educ Program 2012; 198-202 
4 Webert K, Mittal R, Sigouin C et al. A retrospective 11-year-analysis of obstetric patients with idiopathic thrombocytopenic purpura. Blood 2003; 102: 4306-4311

5 Stavrou E, McCrae KR. Immune thrombocytopenia in pregnancy. Hematol Oncol Clin North Am 2009; 23: 1299-1316

6 Crowther MA, Burrows RF, Ginsberg J et al. Review thrombocytopenia in pregnancy: diagnosis, pathogenesis and management. Blood Rev 1996; 10: 8-16

7 Kwon JY, Shin JC, Lee JW et al. Predictors of idiopathic thrombocytopenic purpura in pregnant women presenting with thrombocytopenia. Int J Gynaecol Obstet 2007; 96: 85-88

8 McMillan R, Wang L, Tomer A et al. Suppression of in vitro megakaryocyte production by antiplatelet autoantibodies from adult patients with chronic ITP. Blood 2004; 103: 1364-1369

9 Neunert C, Lim W, Crowther M et al. The American Society of Hematology 2011 evidence-based practice guideline for immune thrombocytopenia. Blood 2011; 117: 4190-4207

10 Provan D, Stasi R, Newland AC et al. International consensus report on the investigation and management of primary immune thrombocytopenia. Blood 2010; 115: 168-186
11 Negi VS, Elluru S, Sibéril S et al. Intravenous immunoglobulin: an update on the clinical use and mechanisms of action. J Clin Immunol 2007; 27: 233-245

12 Alkaabi JK, Alkindi S, Riyami NA et al. Successful treatment of severe thrombocytopenia with romiplostim in a pregnant patient with systemic lupus erythematosus. Lupus 2012; 21: 1571-1574

13 British Committee for Standards in Haematology. Guidelines for the investigation and management of idiopathic thrombocytopenic purpura in adults, children and in pregnancy. Br J Haematol 2003; 120: 574596

14 Koyama S, Tomimatsu T, Kanagawa T et al. Reliable predictors of neonatal immune thrombocytopenia in pregnant women with idiopathic thrombocytopenic purpura. Am J Hematol 2012; 87: 15-21

15 Burrows RF, Kelton JG. Pregnancy in patients with idiopathic thrombocytopenic purpura: assessing the risks for the infant at delivery. Obstet Gynecol Surv 1993; 49: 781-788

16 Palmeira P, Quinello C, Silveira-Lessa AL et al. IgG placental transfer in healthy and pathological pregnancies. Clin Dev Immunol 2012; 2012: 985646

17 Salama A. Current treatment options for primary immune thrombocytopenia. Expert Rev Hematol 2011; 4: 107-118 